\title{
The ozone layer and metered dose inhalers
}

\author{
Louis-Philippe Boulet MD FRCPC \\ Centre de pneumologie de l'Hôpital Laval, Institut de cardiologie et de pneumologie de \\ l'Université Laval, Sainte-Foy, Québec
}

\section{L-P Boulet. The ozone layer and metered dose inhalers. Can Respir J 1998;5(3):176-179.}

\begin{abstract}
The stratospheric ozone layer plays a crucial role in protecting living organisms against ultraviolet radiation. Chlorofluorocarbons (CFC) contained in metered-dose inhalers (MDIs) contribute to ozone depletion and in accordance with the Montreal Protocol on Substances That Deplete the Ozone Layer established 10 years ago, phase-out strageies have been developed worldwide for this category of agents. Alternatives to CFC-containing inhalers have been developed, such as powder inhalers and those using hydrofluoroalkanes (HFAs) as propellants, which have been shown to be as safe and effective as CFC-containing inhalers and even offer interesting advantages over older inhalers. The transition to non-CFC MDIs requires a major effort to make the new products available and to ensure adequate comparision with the previous ones. It also requires a harmonization of actions taken by industry, government, licencing bodies and patients or health professional associations to ensure adequate information and education to the public and respiratory care providers.
\end{abstract}

Key Words: Asthma, Chlorofluorocarbons, Hydrofluoroalkanes, Metered dose inhalers, Montreal Protocol, Ozone

\section{La couche d'ozone et les aérosols-doseurs}

RÉSUMÉ : La couche d'ozone de la stratosphère joue un rôle crucial dans la protection des organismes vivants contre le rayonnement ultraviolet. Les chlorofluorocarbones (CFC) contenus dans les aérosols-doseurs contribuent à l'amincissement de la couche d'ozone et, en accord avec le Protocole de Montréal sur les substances appauvrissant la couche d'ozone signé il y a 10 ans, des stratégies d'élimination de cette classe d'agents ont été développées à l'échelle mondiale. On a trouvé des substituts aux aérosols-doseurs contenant des $\mathrm{CFC}$, comme les inhalateurs à poudre et ceux utilisant les hydrofluoroalcanes (HFA) comme propulseurs, qui se sont révélés aussi sûrs et efficaces que les inhalateurs contenant des CFC et qui offrent même des avantages intéressants par rapport aux anciens inhalateurs. La transition vers des aérosols-doseurs ne contenant pas de CFC exige un effort important pour rendre les nouveaux produits accessibles et pour s'assurer qu'ils se comparent aux inhalateurs utilisés précédemment. Cette transition requiert également une harmonisation des actions prises par l'industrie, le gouvernement, les organismes d'accréditation et les patients ou les associations professionnelles de la santé pour que le public, et les professionnels œuvrant dans le domaine des maladies pulmonaires, soient informés et éduqués de façon adéquate sur ce sujet.

\section{THE MONTREAL PROTOCOL}

In September 1997, the world celebrated the 10th anniversary of the Montreal Protocol on Substances That Deplete the Ozone Layer. The Montreal Protocol is an agreement, signed by more than 160 countries, to take "appropriate measures to protect human health and the environment against effects likely to result from human activities which modify or are likely to modify the ozone layer". It is the first international agreement established to try to prevent a major environmental problem (1).
In 1996, all developed countries agreed to stop production and banish importation of newly produced ozone-depleting substances, one class of which, the chlorofluorocarbons (CFCs), is widely used in metered dose inhalers (MDIs) for asthma and other respiratory diseases. The elimination of CFCs has led government authorities to establish transition strategies for a smooth phase-out of products that rely on CFCs. Along with dry powder inhalers and oral medications, the development of new propellants such as hydrofluoroalkanes (HFAs) has provided alternatives to CFCs, allowing

Correspondence: Dr Louis-Philippe Boulet, Le Centre de pneumologie de l'Hôpital Laval, 2725 chemin Sainte-Foy, Sainte-Foy, Québec G1V 4G5. Telephone 418-656-4747, fax 418-656-4762, e-mail lpboulet@med.ulaval.ca 
the continued use of MDIs in the future. However, these substitutes have many implications that will be discussed below.

\section{THE OZONE LAYER AND POTENTIAL CONSEQUENCES OF OZONE DEPLETION}

The stratospheric ozone layer is a protective natural band located between 15 and $35 \mathrm{~km}$ above the earth. It plays a crucial role in absorbing ultraviolet (UV) radiation and, in so doing, protects humans and the environment from the damage caused by this type of radiation (2). Ozone depletion allows increased penetration of the earth's atmosphere by type B UV rays (UVB), the most significant type of UV radiation with regard to health and environmental consequences (3). Increased exposure to UVB may increase the occurence of cataracts and skin cancer, particularly melanoma, diseases whose prevalence has markedly increased in the past decade, particularly in the southern hemisphere $(4,5)$. It may also impair the immune defences of living organisms. UVB rays can also affect basic crops, such as soybeans, and destroy organisms placed at the first steps of the ocean food chain, such as phytoplankton and krill.

\section{CAUSES OF OZONE DEPLETION}

Ozone depletion, first hypothesized in 1974, was confirmed in 1985 by a British Antarctic survey team that found a marked thinning of the ozone layer over the South Pole. In 1989 , the size of this 'ozone hole' was estimated to be 25 million $\mathrm{km}^{2}$, and it seems to be growing. It is now estimated to be approximately the size of North America.

The thickness of the ozone layer is affected by various natural factors, including volcanic eruptions, but one of the major depleting factors is the increasing quantity of substances such as CFCs in the atmosphere that destroy ozone by transforming it to chlorine monoxide and oxygen. More specifically, ozone-depleting substances include molecules such as hydrochlorofluorocarbons (HCFCs), methyl bromide, methylchloroform, carbon tetrachloride, various brominecontaining halons and many $\mathrm{CFCs}$, including the frequently used CFC 11 and CFC 12. CFCs and halons are considered to be the main ozone layer depleters.

It is believed that one CFC molecule can destroy up to 100,000 ozone molecules. Furthermore, increased quantities of CFCs in the atmosphere appear to speed up the greenhouse effect. CFCs are entirely man-made substances that were invented in 1920. They have been the most widely used refrigeration agents in refrigerators and air-conditioners, and they are used for foaming plastic insulation, as propellants in MDIs, as extinguishing agents and for special cleaning purposes. In 1991, an estimated 1.1 million tonnes of CFCs were used, 6400 tonnes coming from a vareity of aerosol products. In 1991, MDIs accounted for about $1 \%$ of all CFCs used, but since the signing of the Montreal Protocol, this percentage has increased significantly as the use of CFCs for other purposes has declined.

Unfortunately, CFCs are projected to last 100 years or more in the atmosphere. Even with a complete cessation of CFC production, it will probably take many decades to re- store the thickness of the ozone layer to its pre-CFC condition. The potential for increased transmission of UV radiation will therefore exist for at least another century, and while little damage due to increased UV radiation seems to have occurred so far, the potential for long term problems is impressive.

\section{INTERNATIONAL INITIATIVES TO PROTECT THE OZONE LAYER}

In response to the projected consequences of ozone depletion, the 1985 Vienna Convention provided a framework for international restrictions on the production of ozonedepleting substances. This was followed in 1987 by the Montreal Protocol on Substances That Deplete the Ozone Layer. Since then, various amendments have been drawn up to establish deadlines for halting the production and use of CFCs. The use of CFCs has been banished with only two exceptions: for medical use, mostly for MDIs, and to meet some technical needs for space programs. The Montreal Protocol works under the auspices of the United Nations Environmental Program (UNEP), and relevant decisions are made at meetings of the countries that have ratified the Montreal Protocol. The Technical and Economic Assessment Panel (TEAP) is one of three expert advisory panels that provides information on how fast the world can reasonably expect to implement a reduction of ozone-depleting substances emissions and on the likely costs of such a phase-out. The TEAP coordinates the work of seven technical options committees (TOCs) that look at the different areas in which ozone-depleting substances are used. The TOCs are groups of experts who study the feasibility of phasing out in their own areas of expertise. They make recommendations, and the TEAP may endorse the recommendations. Transition strategies are the responsibility of individual countries, and they are implemented at the national level.

Responding to the decision to eliminate CFCs, the pharmaceutical industry has devoted major resources to developing replacement substances. At present, more than 1400 scientists in 90 laboratories in at least 10 countries are working to develop replacement products with new propellants. The pharmaceutical industry has already spent at least one billion dollars on this project, and they anticipate spending much more to complete it (6).

\section{CFC-FREE MDIs}

Alternatives to CFC-containing inhalers come in various forms. Several different dry powder inhalers are availaible, and some new asthma drugs have been developed in oral form (eg, leukotriene antagonists). However, MDIs still constitute $75 \%$ of all inhalers used in the treatment of diseases such as asthma, and the number of inhalers used has been increasing steadily over the past few years. In fact, the number is expected to continue to increase for several more years. More than 400 million inhalers are used around the world each year.

In March 1995, the first approval for a CFC-free MDI was granted in the United Kingdom to 3M's Airomir, an HFA- 
134a reformulated salbutamol (7). Airomir has been approved in Canada recently and is now available. ProventilHFA, which is salbutamol with HFA-134a as a propellant, was approved by the United States Food and Drug Administration in August 1996. HFAs are nonflammable and chlorine-free, and they are believed to have no impact on the ozone layer. Toxicology studies have shown them to be safe for human use, and recent research demonstrated that the bronchodilating effects of HFA-salbutamol were similar to CFC-salbutamol (8).

Inhalers containing HFAs have been approved in more than 35 countries, and many pharmaceutical companies are about to introduce new CFC-free inhalers. The international pharmaceutical aerosol consortium (IPAC) recently predicted that by the end of 2000 , there will be at least 36 CFCfree MDIs in the European Union, 11 in the United States and 33 in at least one other developed country.

The use of new HFA propellants has made it necessary to redesign not only MDI formulations but also the MDI hardware, a process that has led to interesting findings on the properties of these new devices. Indeed, it was determined that the inhalers' propellant was not the only thing that had to be changed but that different surfactants and new value design were also required because of the change in propellant. One of the features observed with the first HFAinhalers, such as Airomir, was that the doses produced were more consistent from the first to the last dose when used to exhaustion ('tail-off'). They did not have the 'loss of dose' effect, a reduced dose for the first puff and enrichment of the second when actuated after storage. Furthermore, unlike CFC inhalers, they were minimally affected by cold temperatures. In addition, these new inhalers deliver a smaller volume of aerosol with each actuation than CFC-MDIs did, thus patients may note a comparatively 'softer puff' and less propellant sensation from the effect of cold freon (9). The particle size of the salbutamol aerosol was similar for that of CFC and HFA formulations, and the new inhalers deliver the same quantity of medication (10).

\section{A NATIONAL STRATEGY TO ELIMINATE CFC}

Canada and most other countries are developing phaseout strategies for metered dose inhalers containing CFCs and transition to the use of HFA inhalers. This transition strategy should ensure the safety and efficacy of the new therapeutic agents as well as patient acceptance and preservation of the patient-physician relationship. It should also address the cost concerns of the different parties involved. Particularly, physicians should be aware of the consequences of this phaseout and be able to transmit this information to their patients (9). In this regard, a recent survey conducted by the Canadian Lung Association has shown that patients' acceptance of new non-CFC inhalers depended primarily on the advice of their physician (11).

Among other elements to be considered when forming the transition strategy are access to the new non-CFC inhalers, their cost and pricing, and the competitiveness of the pharmaceutical industry. Of critical importance is the question of how the replacement of existing products will be accomplished effectively while ensuring patient safety.

It is essential that educational interventions be addressed not only to health care providers, but also to asthma patients to avoid misunderstandings and unreasonable fears. These efforts should be coordinated with the regional lung associations and other organizations involved in asthma education at both national and provincial levels. The time-frame of the phase-out is crucial; it should allow a smooth transition and therefore promote physicians' and patients' acceptance through effective dissemination of information, and it should reflect the spirit of the Montreal Protocol and encourage a rapid elimination of CFCs.

At the September 1997 meeting of the parties of the Montreal Protocol, the participants indicated that non-Article 5 countries (ie, developed countries such as Canada) should have ideally completed or almost completed the transition to non-CFC MDIs by the year 2000. More realisitically, as other countries, Canada should have achieved a substantial reduction of CFC-MDI by 2001 and a complete phaseout in 2005. Developing countries have until January 31, 1999 to have a transition strategy in place.

Various strategies have been suggested for dealing with the replacement of current CFC products.

- By category: When sufficient CFC-free alternatives to a drug category are available, the remaining CFC products in that category can be phased out.

- By drug: At a given time after a reformulated CFC-free MDI has become available for one type of drug (eg, salbutamol, beclomethasone, etc) other CFCs-MDI containing the same substance can be withdrawn over a certain time period.

- By brand: When a company produces a new CFC-free MDI, it can replace the existing product.

A 'sunset date', indicating a specified date by which the quantity of CFC-free (or the number of CFC inhalers) is to be gradually reduced to zero, may also be added to the different options. A recent survey of the Canadian Thoracic Society Asthma Committee Members showed that the drug-by-drug option was generally the more popular option.

The decision regarding which of these approaches will be enforced is likely to have major consequences on patient acceptance. It may also affect the cost of treatment, although the industry has indicated that CFC-free inhalers will be sold at a competitive cost to the existing brand-name products.

Assessing the comparative effects of the new products against those of the old ones, particularly of inhaled corticosteroids, will require a major effort. Indeed, recent studies have suggested that the deposition of HFA-beclomethasone in the peripheral lung was increased compared with that of CFC-beclomethasone in asthma treatment; the increased deposition of HFA-beclomethasone leads to superior efficacy compared with its CFC counterpart (12). Of course, more studies will have to be completed on the different compounds using the new propellants to establish their comparative safety and efficacy profile. This will constitute a major task of regulatory agencies in the near future. Finally, 
because doctors have limited experience with the new inhalers, a postmarketing surveillance program will be required, looking at safety and efficacy, but at the acceptance of the new products by caregivers and patients.

All of these issues require harmonization of efforts by industry, government, licencing bodies, and patient and health professional organizations. Consultation meetings of stakeholders took place in July and December 1997 to voice opinions and allow discussions regarding the Canadian strategy for the phase-out of ozone-depleting substances. Further consultations are ongoing to complete this exercise and an education and awareness steering committee has been nominated to coordinate the education efforts aimed at health care professionals, patients and the general public. We should therefore hear more about new initiatives in the next few months.

ACKNOWLEDGEMENT: I thank Pr Myrna Dolovich for reviewing this manuscript.

\section{REFERENCES}

1. United Nations Environmental Program. Montreal Protocol on Substances that Deplete the Ozone Layer: Technology and Economic
Assessment Panel, vol I and II. Report Vol I and II. The Netherlands: United Nations Environment Programm, 1997.

2. Environment Canada. Canada's Ozone Layer Protection Program A Summary, 3rd edn. Ottawa: Environment Canada, 1996.

3. Leaf A. Ozone depletion and public health. Hosp Pract 1994;29:9-10.

4. Slaper H, Velders GJ, Daniel JS, de Gruijl FR, van der Leun JC.

Estimates of ozone depletion and skin cancer incidence to examine the Vienna Convention achievements. Nature 1996;384:256-8.

5. Coldiron BM. Ozone depletion update. Dermatol Surg 1996;22:296-9.

6. International Pharmaceutical Aerosol Consortium. Ensuring patient care - The role of HFC MDI. IPAC. Washington: IPAC, 1997.

7. Kleerup EC, Tashkin DP, Cline AC, Ekholm BP. Cumulative dose-response study of non-CFC propellant HFA 134a salbutamol sulfate metered dose inhaler in patients with asthma. Chest 1996;109:702-7.

8. Leach C. Safety assessment of the HFA propellant and the new inhaler. Eur Respir Rev 1997;41:35-6.

9. June D. Achieving the change: challenges and successes in the formulation of CFC-free MDIs. Eur Respir Rev 1997;41:32-4.

10. Matthys H. CFCs and their effect on the ozone layer: the Montreal Protocol and consequences for physicians. Eur Respir Rev 1997;41:29-31.

11. The Lung Association. Issues relating to the transition to CFC-free metered dose inhalers and asthma patients [Report]. Toronto: Canada Market Research Ltd, June 1997.

12. Dahl R, Ringdal N, Ward SM, Stampone P, Donnell D. Equivalence of asthma control with new CFC-free formulation HFA-134a beclomethasone dipropionate and CFC-beclomethasone dipropionate. Br J Clin Pract 1997;51:11-5. 


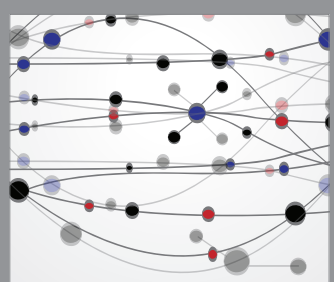

The Scientific World Journal
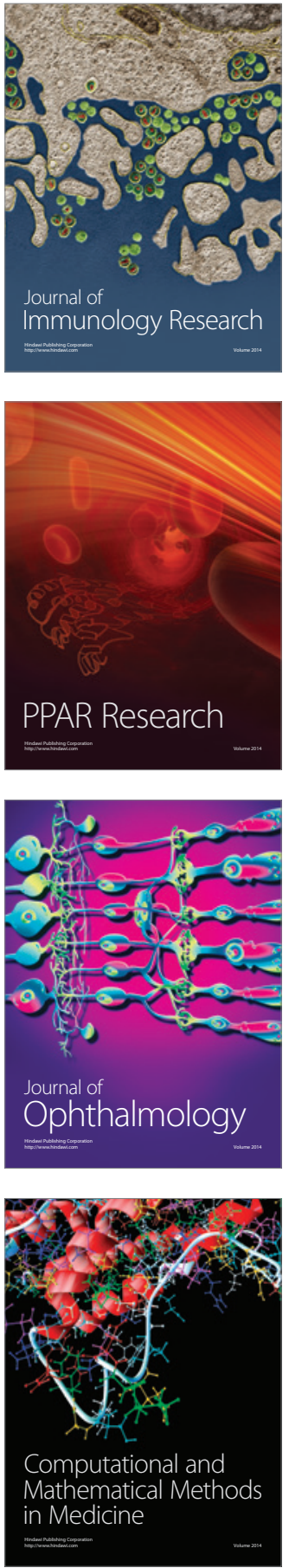

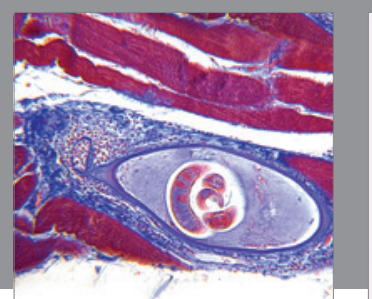

Gastroenterology Research and Practice

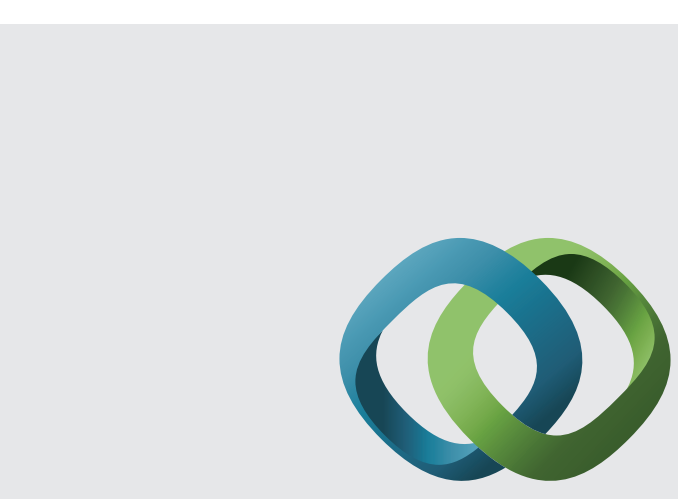

\section{Hindawi}

Submit your manuscripts at

http://www.hindawi.com
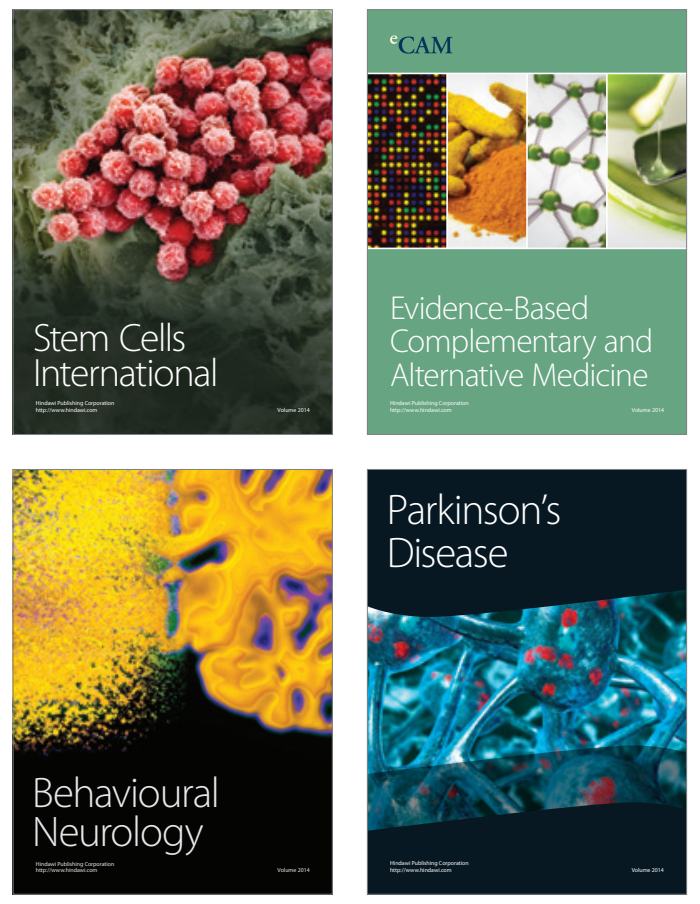
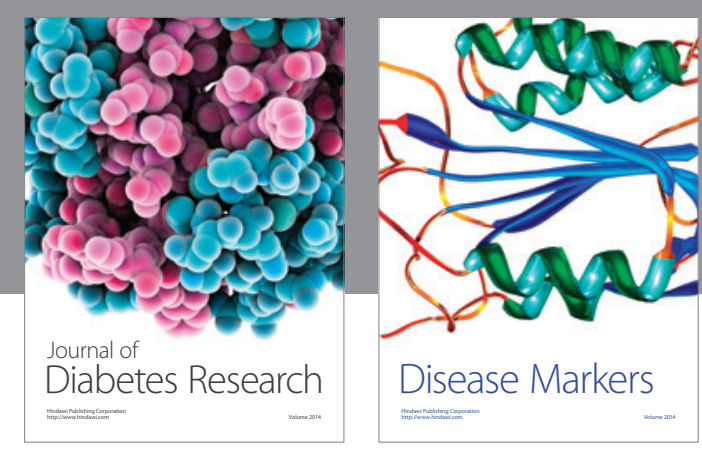

Disease Markers
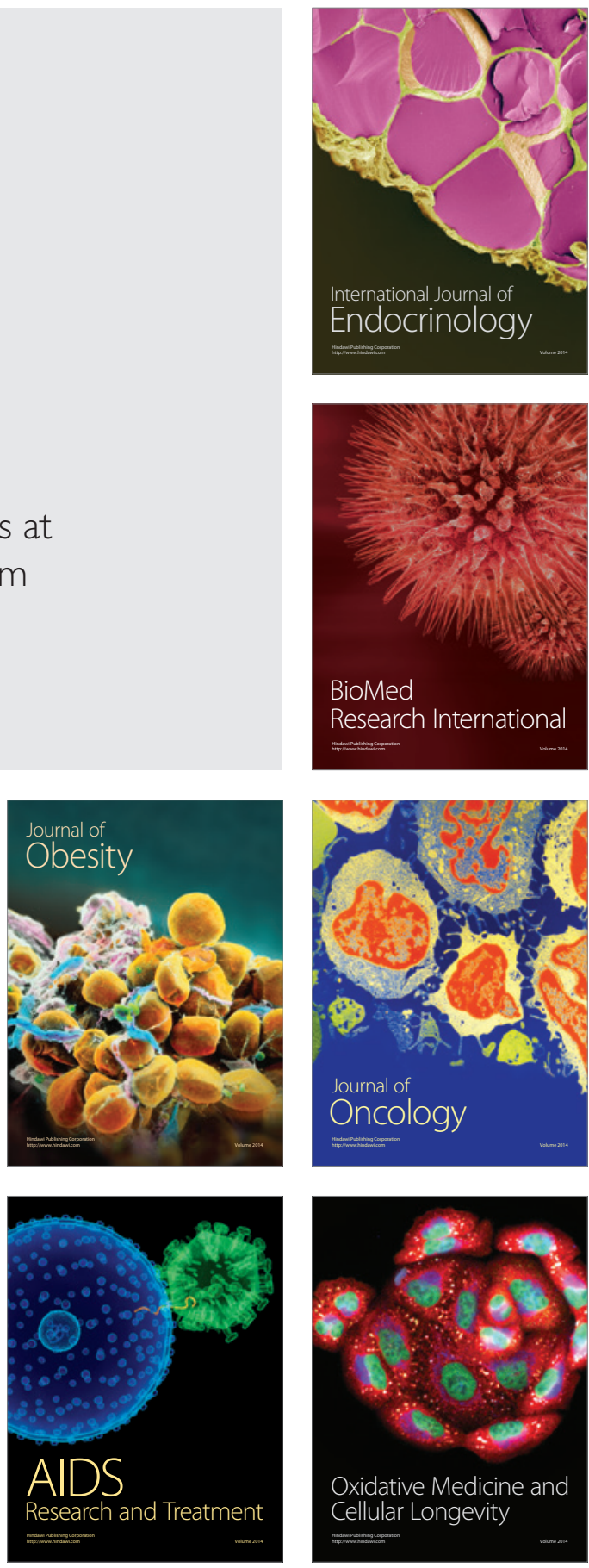